\begin{tabular}{lcr} 
Produkt & $\begin{array}{r}1936-1939 \\
\text { (Jahresmittel) }\end{array}$ & 1954 \\
\hline Weizen & 210 & 235 \\
Roggen & 353 & 132 \\
Gerste & 189 & 262 \\
Hafer & 754 & 773 \\
Kartoffeln & 1337 & 1089 \\
Butter & 55 & 65 \\
Käse & 10 & 23 \\
Rindfleisch & 52 & 53 \\
Schweinefleisch & 56 & 67
\end{tabular}

Die Zeit der «schwendenden Bauern» ist schon längst vorbei. Der Wald wird nicht mehr rücksichtslos niedergebrannt und das Korn gleich darauf in die Asche gesät. Bis über den Polarkreis hinaus wird heute der Boden meist nach modernen Methoden bearbeitet, und kein anderes europäisches Land besitzt im Verhältnis zum Gesamtareal in diesen hohen nördlichen Breiten noch eine derart große Landwirtschaftsfläche wie das mutige Finnland!

\title{
EINSAMES VOLK IM HINTERLAND BRASILIENS
}

\section{RUdOLF STREIFF-BeCKER}

In Brasilien, der größten Republik Südamerikas, gibt es im Landesinneren noch ausgedehnte Landstriche, die unerforscht und nur teilweise und ungenau kartiert sind. Dort leben noch Sippen primitiver Indianer frei im zentralbrasilianischen Busch und Urwald, betreut vom staatlichen «Dienst zum Schutz der Indianer». Zwischen dem Wohngebiet der Indianer und den Küstenländern, wo die Kulturbevölkerung ihre intensive Tätigkeit entfaltet, liegt ein breiter, schwach bevölkerter Streifen Landes, mit wenig Ortschaften, deren Gründung zum Teil in die Kolonialzeit zurückreicht.

Im Jahre 1957 lief die Nachricht durch das Land, es sei im Hinterland (im «Sertão») des Staates Paraibo do Norte ein bisher unbekannter Indianerstamm entdeckt worden. Diese Kunde erregte nicht nur Ethnographen und Geographen, sondern auch weite Kreise der gebildeten Bevölkerung. Die bedeutende Zeitung «O Estado de São Paulo» beauftragte ihren Korrespondenten in der Stadt João Pessosa im Staat Paraiba do Norte, womöglich eine kompetente Persönlichkeit zur Auskundschaftung der fraglichen Gegend zu entsenden, was auch geschah. Die genannte Zeitung veröffentlichte in ihren Ausgaben vom 1., 3. und 4. September 1957 die Ergebnisse der Expedition, deren wesentliche Teile im folgenden wiedergegeben seien.

Die Nachricht von der Existenz eines unbekannten, namenlosen Völkleins war nach der Stadt Santa Luzia durch einen Mann, namens Julio VieIRA gebracht worden. Dieser, ein pensionierter Unteroffizier der brasilianischen Armee, war einst aus Abenteuerlust in den Sertão gezogen. Er war bei ungefähr 6 bis $7 \mathrm{Grad}$ südl. Breite, in der Serra do Talhado, auf einsam lebende Menschen dunkler Hautfarbe gestoßen und als Lehrer und Berater unter ihnen geblieben. Später kehrte er jedoch entmutigt wieder nach Santa Luzia zurück und bewirkte durch seine Erzählungen die eingangs erwähnte Nachricht von der Entdeckung unbekannter Indianer. In Santa Luzia kennt man nun schon seit langem gewisse Caboclos, die gelegentlich aus dem Inneren zu den Jahrmärkten der Stadt kommen, durch ihre eigenartige Kleidung auffallen, stets ein Buschmesser mit langem Griff im Gürtel tragen, dem Zuckerrohrschnaps zugetan sind und unter dessen Wirkung sehr rauflustig werden. Sie bringen auf den Jahrmarkt eigenartige Tongefäße, die sie gegen fremde Waren eintauschen. Ihre blau- 


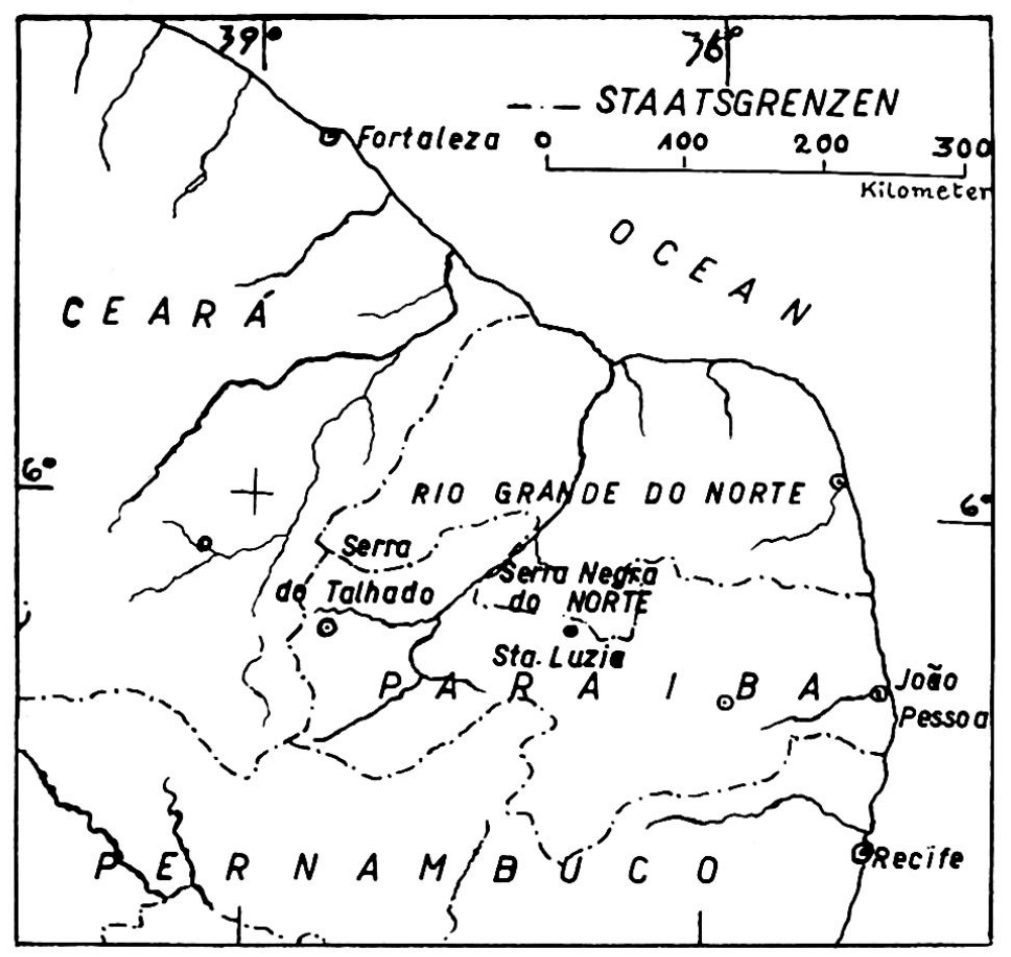

Orientierungskizze

des Gebietes der Serra do Talhado

grauen Töpfereien sind sehr beliebt, weil darin aufbewahrte Flüssigkeiten viel länger kühl bleiben als in den landesüblichen roten Tongefäßen. Es ergab sich deshalb die Vermutung, daß es sich bei den erwähnten Indianern um Abkömmlinge solcher Cablocos handeln könnte, die lediglich der Vergessenheit anheimgefallen seien.

Der Korrespondent der Zeitung «O Estado de São Paulo», Herr Dolcidio dE Moreira, machte sich mit einem landkundigen Begleiter auf die Reise, die sehr lang und mühsam war. Sie führte durch Landschaften der Nordostzone Brasiliens, die wegen öfteren Auftretens katastrophaler Trockenperioden berüchtigt sind, welche Hungersnöte im Gefolge haben. Das Land ist dort fast unbewohnt, es besteht aus pfadlosen, fast wüstenhaften Hochflächen, wo Wasser und Wind ungehemmt arbeiten und besonders an den weichen Felsen umrahmender Gebirge und an den Steilborden breiter Flußläufe phantastische Erosionsformen erzeugen. Die herrschende Hitze, der streckenweise bestehende Wassermangel, die dunstige Luft, die pflanzenund tierarme Landschaft wirkten ermüdend auf die Reisenden.

Schließlich stießen sie in einer Gegend der Stille und Einsamkeit auf einige primitive Häuser, die so weit von einander gelegen sind, daß man kaum von einer Ortschaft sprechen konnte. Die dunkelhäutigen Bewohner erwiesen sich als Leute, die portugiesisch sprachen, wenn dies auch nur in kurzen Sätzen und in singendem Tonfall geschah. Bleibender Aufenthalt in solcher Landschaft ist nur Menschen möglich, die mit überlegten Methoden zu arbeiten verstehen. Verweichlichte Geschöpfe würden untergehen. Andrerseits formt die harte Natur hier den Bewohner zum zähen Kämpfer. Es mögen etwa 500 Seelen sein, die in rund 900 Metern Meereshöhe in der Serra do Talhado leben. Sie sind arm, zeigen jedoch eine bemerkenswerte Gesundheit und auch eine gewisse Schönheit.

Es ist wahrscheinlich, daß sich das Volk der Serra do Talhado aus Gruppen von Negersklaven entwickelt hat, die zur Kolonialzeit aus Zucker- und Baumwollpflanzungen der Küsten entflohen sind, sich in den fernen Bergen zusammenfanden, um dort in der Verborgenheit nach Sitten und Gebräuchen zu leben, die sie oder ihre Vorfahren von Afrika her gewohnt waren. Mit ihnen vermischten sich wohl in der Folge Menschen weißer Hautfarbe, die auf der Suche nach wertvollen Hölzern sich in jene fernen Gegenden verirrten, und bei ihnen blieben. Es ist jedoch merkwürdig, 
daß bei dieser Bergbevölkerung, trotz dem niederen Bildungsstand die Tendenz zur Rassentrennung, eine gewisse Scheu vor Vermischung zu beobachten ist. Der Export seltener Hölzer hielt wahrscheinlich im Anfang die Verbindung mit der Kulturbevölkerung der Küstengegend noch aufrecht. Als dann aber diese Hölzer immer spärlicher zu finden waren, drohte die gänzliche Vereinsamung. Zum Glück für die Bevölkerung fand ein anderes Produkt, nämlich ihre Tongefäße, Anklang bei den Küstenbewohnern. Die Bewohner des Sertãos begannen aus dem blaugrauen Ton ihres Landes Gefäße herzustellen, die wegen ihrer Porosität ein Maximum von Verdunstungskälte erzeugen. Darin aufbewahrte Flüssigkeiten bleiben deshalb auch bei größter Hitze stets viel kühler, als in den Gefäßen aus rotem Ton, die sonst in Brasilien allgemein verwendet werden. Wegen dieser Eigenschaft finden die blaugrauen Gefäße aus der Serra do Talhado auf den Jahrmärkten guten Absatz. Die kleine Industrie ermöglicht daher den Bewohnern des Sertãos ein bescheidenes Dasein.

Dolcidio de Moreira forschte in den Archiven von Santa Luzia und noch anderen Orts nach, um Näheres über die Geschichte der Besiedlung des Gebietes zu erfahren. Aus den sehr spärlichen Dokumenten ging hervor, daß die ersten Bewohner das Land in der Serra do Talhado im Jahre 1702 in Besitz genommen hatten. Die Zivilregister von Santa Luzia enthalten indes nur wenige, summarische Angaben über die Bewohner des Sertãos. Moreira kam aber zu der überzeugenden Ansicht, daß hier kein neuer Indianerstamm entdeckt worden sei, sondern nur eine Art verborgener «Favela». Favela nennt man bekanntlich die Siedelungen in versteckten Winkeln der Vorstädte von Rio de Janeiro, wo nach der Sklavenbefreiung Neger ihre primitiven Behausungen aus Bambus, Sapégras, Lehm und altem Blech errichtet hatten, und wo sie ihr einfaches Leben nach ererbten afrikanischen Gebräuchen vermischt mit europäischen Sitten und Unsitten verbringen.

Die Flucht von Sklaven aus der Küstenzone nach den einsamen Weiten des Hinterlandes wurde häufiger, als in der zweiten Hälfte des letzten Jahrhunderts der Einfluß der Parteien für Aufhebung der Sklaverei mächtiger wurde und freiheitlichere Gesetze erlassen wurden. Es sei in diesem Zusammenhang hier an einige geschichtliche Daten erinnert:

Im Jahre 1849 wurde durch einen Transport von Negersklaven aus Afrika das gelbe Fieber nach Brasilien eingeschleppt, das lange Zeit hier in furchtbarer Weise wütete. Im Jahr 1850 wurde deswegen das Verbot des Imports von Sklaven aus Afrika erlassen. 1871 wurde sodann auf Antrag des verdienstvollen Staatsmannes Barao do Rio Branco ein Gesetz erlassen, wonach Kinder von Sklavinnen von Geburt an frei sein sollen. Endlich wurde im Jahr 1888 durch das «Lei Aurea» genannte Gesetz die Sklaverei in Brasilien überhaupt aufgehoben. Damit entfiel naturgemäß auch der Anlaß zur Flucht von Sklaven, während umgekehrt die Isolierung der Bevölkerungen gewisser Gebiete sich steigerte. Die «Neu»entdeckung wird aber vielleicht doch dazu beitragen, daß diese Isolierung sich in absehbarer Zeit in fruchtbare Kontakte verwandelt.

\section{UN PEUPLE ISOLÉE DANS L'ARRIÈRE-PAYS BRÉSILIEN}

Il y a quelques années parvint de l'intérieur du Brésil une nouvelle selon laquelle on aurait découvert un peuple indien inconnu jusqu'ici. Le journal «O Estado de São Paulo» envoya un collaborateur sur place pour apprendre si cela correspondait aux faits. Le correspondant, D. DE Moreira, trouva des habitants à la peau foncée qui parlaient le portugais et demeuraient dans des huttes primitives. D'après ses recherches, il s'agit de descendants d'anciens esclaves noirs qui s'étaient enfuis des plantations et qui étaient, depuis lors, tombés dans l'oubli. 